\title{
Effects of substrates and foliar fertilizer on growth and development of Lisianthus (Eustoma grandiflorum (Raf.) Shinn) in Ho Chi Minh City
}

\author{
Duong T. T. Pham*, Cuong C. Nguyen, Duong N. Le, \& Ngan T. T. Tran
}

Faculty of Agronomy, Nong Lam University Ho Chi Minh City, Ho Chi Minh City, Vietnam

\begin{abstract}
ARTICLE INFO
Research Paper

Received: August 11, 2019

Revised: September 22, 2019

Accepted: October 25, 2019

\section{Keywords}

Floria fertilizer

Lisianthus

Substrate

\section{* Corresponding author}

Pham Thi Thuy Duong Email: pttduong@hcmuaf.edu.vn

\section{ABSTRACT}

Lisianthus (Eustoma grandiflorum (Raf.) Shinn) is a favorable flower plant for decoration year-around, especially during New Year holiday. This experiment was conducted in order to evaluate influences of five substrates and three concentrations of foliar fertilizer on growth and development of Lisiathus in Ho Chi Minh City. The obtained results indicated that the plants which were grown best on the substrate mixture of $30 \%$ cow dung : $40 \%$ coco peat : $20 \%$ rice husk ash : $10 \%$ soil had better plant height $(46.06 \mathrm{~cm})$, number of leaves (63.30 leaf/plant), number of flower buds (14.20 buds/plant) and number of flower (6.17 flowers/plant) than the other treatments. Lisianthus grown on the substrate mixture of $30 \%$ cow-dung : $40 \%$ coco peat : $20 \%$ rice husk ash : 10\% soil mixed foliar fertilizer Dau Trau MK 30-10-5 at a concentration of $2.0 \mathrm{~g} / \mathrm{L}$ was highest in the plant height $(46.80 \mathrm{~cm})$ and number of leaves (66.00 leaves/plant). However, the number of flower buds and number of flower were 15.47 buds/plant and 7.53 flowers/plant, respectively when Lisianthus was grown on substrate $30 \%$ cow-dung : $40 \%$ coco peat : $20 \%$ rice husk ash : $10 \%$ soil mixed foliar fertilizer at a concentration of $1.0 \mathrm{~g} / \mathrm{L}$.
\end{abstract}

Cited as: Pham, D. T. T., Nguyen, C. C., Le, D. N., \& Tran, N. T. T. (2020). Effects of substrates and foliar fertilizer on growth and development of Lisianthus (Eustoma grandiflorum (Raf.) Shinn) in Ho Chi Minh City. The Journal of Agriculture and Development 19(1), 9-15. 


\title{
Ảnh hưởng của giá thể và nồng độ phân bón lá đến sinh trưởng và phát triển cây hoa cát tường (Eustoma grandiflorum (Raf.) Shinn) trồng chậu tại Thành phố Hồ Chí Minh
}

\author{
Phạm Thị Thùy Dương*, Nguyễn Chí Cường, Lê Nhựt Dương \& Trần Thị Trang Ngân \\ Khoa Nông Học, Trường Đại Học Nông Lâm TP.HCM, TP. Hồ Chí Minh
}

THÔNG TIN BÀI BÁO
Bài báo khoa học
Ngày nhận: 11/08/2019
Ngày chỉnh sửa: $22 / 09 / 2019$
Ngày châpp nhận: $25 / 10 / 2019$
Từ khóa
Cây hoa cát tường
Giá thể
Phân bón lá
*Tác giả liên hệ
Phạm Thị Thùy Dương
Email: pttduong@hcmuaf.edu.vn

\section{1. Đặt Vấn Đề}

Cây hoa cát tường là loại cây trồng ôn đới, có khả năng kháng bệnh và đáp ứng stress nhiệt độ cao (Tran, 2015). Hiện nay, cây hoa cát tường được trồng nhiều ở Lâm Đồng và một số tỉnh miền Bắc Việt Nam. Hoa cát tường rất được thị trường ưa chuộng vì màu sắc, kích cỡ, hình dạng của hoa rất đa dạng, hoa bền đẹp. Thành phố Hồ Chí Minh là thị trường tiêu thụ hoa kiểng lớn nhất nước, mặc dù sản lượng hoa trồng chậu (bao gồm hoa cát tường) ước tính đạt 6,7 triệu chậu nhưng vẫn chưa đáp ứng đủ nhu cầu cây trồng chậu của thành phố (HCMCPC, 2016). Chi phí vận chuyển hoa cát tường từ vùng sản xuất đến nơi tiêu thụ cao làm cho giá thành hoa cát tường tăng cao. Vì vậy, cần áp dụng các biện pháp kỹ thuật thích hợp để có thể đa dạng vùng trồng cho loài cây này.

Đối với cây trồng chậu, giá thể đóng vai trò quan trọng trong việc cung cấp không khí, nước, cho phép rễ phát triển tối đa và đáp ứng các tính chất vật lý cho cây trồng (Olle \& ctv., 2012). Trồng cây trên giá thể giúp bộ rễ thông thoáng, do đó cung cấp đủ oxy cho vùng rễ nên cây phát triển khỏe mạnh. Đồng thời, sử dụng giá thể để trồng cây còn giúp tận dụng hiệu quả các phụ phẩm nông nghiệp và thuận lợi cho việc vận chuyển. Tuy nhiên, mỗi loại giá thể có đặc tính khác nhau, do đó cần thiết phải xác định loại giá thể thích hợp nhằm giúp cây trồng sinh trưởng tốt, hạn chế bệnh hại.

Bên cạnh đó, để cây trồng sinh trưởng và phát triển tốt thì việc bổ sung các chất dinh dưỡng là điều cần thiết. Trong đó, phân bón lá giúp cung cấp các chất dinh dưỡng một cách nhanh chóng và hiệu quả, giúp cải thiện tình trạng sinh lý của cây (Bui, 2013). Mỗi cây trồng có nhu cầu dinh dưỡng khác nhau nên cần thiết phải xác định nồng độ phân bón thích hợp vừa giúp cây sinh trưởng tốt, vừa mang lại hiệu quả kinh tế cao. Do đó, mục tiêu của nghiên cứu nhằm đánh giá ảnh hưởng của giá thể và nồng độ phân bón lá đến sinh trưởng và phát triển của cây hoa cát tường 
(Eustoma grandiflorum (Raf.) Shinn) trồng chậu tại Thành phố Hồ Chí Minh.

\section{Vật Liệu và Phương Pháp Nghiên Cứu}

\subsection{Thời gian và địa điểm nghiên cứu}

Thí nghiệm được thực hiện từ tháng 10/2018 đến tháng 03/2019 tại Trại Thực nghiệm Khoa Nông học, Trường Đại học Nông Lâm Thành phố Hồ Chí Minh.

\subsection{Phương pháp nghiên cứu}

\subsubsection{Vật liệu nghiên cứu}

Xơ dừa: Xơ dừa tươi được thu thập tại các cơ sở chế biến chỉ xơ dừa tại huyện Giồng Trôm, tỉnh Bến Tre. Xơ dừa được ngâm trong nước vôi $\mathrm{CaCO}_{3}(10 \%)$ trong thời gian 14 ngày và xả lại 2 lần với nước sạch để giảm bớt hàm lượng tanin.

Tro trấu: Là sản phẩm thu được sau khi đốt vỏ trấu, có nguồn gốc từ tỉnh Long An. Tro trấu được ngâm với nước sạch trong thời gian 2 tuần để giảm giá trị EC.

Phân bò: Phân bò đã được ủ hoai trong thời gian 30 ngày, do Trại thực nghiệm Khoa Chăn nuôi - Thú y, Trường Đại học Nông Lâm TP.HCM cung cấp. Phân bò trước khi phối trộn được phơi để giảm ẩm độ cũng như được làm tơi để giá thể được đồng đều.

Đất: Đất được sử dụng là lớp đất mặt dày 15 cm (đất xám bạc màu tại Thủ Đức, Thành phố Hồ Chí Minh). Đất được băm nhuyễn và phơi trực tiếp dưới ánh sáng mặt trời để diệt một số tác nhân gây hại có trong đất.

Chế phẩm Trichoderma được sản xuất và phân phối bởi công ty TNHH Điền Trang, có chứa $1 \times$ $10^{8} \mathrm{CFU} / \mathrm{g}$ bào tử nấm Trichoderma spp.

Vôi $\mathrm{CaCO}_{3}$ (40\% Ca) dạng bột.

Phân bón lá: Phân bón Đầu Trâu MK 30-10-5, dạng hạt do công ty TNHH Bình Điền MeKong sản xuất và phân phối; có chứa $30 \% \mathrm{~N}, 10 \%$ $\mathrm{P}_{2} \mathrm{O}_{5}, 5 \% \mathrm{~K}_{2} \mathrm{O}$. Phân bón lá được phun định kì 7 ngày/lần, tương ứng với các nồng độ thí nghiệm. Lượng phun: $120 \mathrm{~mL} /$ cây.

Phân bón gốc: Phân NPK 20-20-15 + TE, dạng hạt, do công ty cổ phần phân bón Bình Điền phân phối và sản xuất, được bón định kỳ 15 ngày/lần, bắt đầu từ 15 NST với lượng $1,5 \mathrm{~g} /$ chậu.

Cây giống hoa cát tường màu hồng được gieo từ hạt trong 50 ngày có đủ 6 lá thật, không có triệu chứng của sâu bệnh gây hại, do công ty TNHH Hạt giống hoa Việt Nam cung cấp.

Chậu trồng: Có đường kính mặt $\times$ đường kính đáy $\times$ chiều cao $=18 \times 12 \times 18 \mathrm{~cm}$.

Các vật liệu như xơ dừa, tro trấu, phân bò và đất được phối trộn theo tỉ lệ thể tích tương ứng với từng nghiệm thức. Lượng giá thể được cho vào chậu có thể tích $2592 \mathrm{~cm}^{3}$.

\subsubsection{Bố trí thí nghiệm}

Thí nghiệm hai yếu tố được bố trí theo kiểu hoàn toàn ngẫu nhiên với ba lần lặp lại. Yếu tố thứ nhất gồm 5 loại giá thể: (G1) $20 \%$ phân bò : $20 \%$ xơ dừa : $40 \%$ tro trấu : $20 \%$ dất (đối chứng), (G2) $20 \%$ phân bò : $40 \%$ xơ dừa : $20 \%$ tro trấu : $20 \%$ dât, (G3) 30\% phân bò : $20 \%$ xơ dừa : $30 \%$ tro trấu : $20 \%$ đất, (G4) $30 \%$ phân bò : $40 \%$ xơ dừa : $20 \%$ tro trấu : $10 \%$ đất và (G5) $10 \%$ phân bò : $30 \%$ xơ dừa : $40 \%$ tro trấu : $20 \%$ dất; yếu tố thứ hai gồm 3 nồng độ phân bón lá Đầu Trâu MK 30-10-5: 0,5 g/L (P1), 1,0 g/L (P2) (đối chứng) và $2,0 \mathrm{~g} / \mathrm{L}$ (P3). Phân bón lá được phun định kỳ 7 ngày/lần, tương ứng với các nồng độ thí nghiệm. Lượng phun là $120 \mathrm{~mL} /$ cây.

Thí nghiệm gồm 15 nghiệm thức, mỗi nghiệm thức được lặp lại 3 lần, mỗi lần có 15 chậu, tổng số chậu thí nghiệm là 675 chậu.

Các chỉ tiêu theo dõi cây trồng bao gồm: Chiều cao cây $(\mathrm{cm})$ : đo từ vị trí vết sẹo cặp lá dưới cùng đến đỉnh sinh trưởng của chồi cao nhất trên cây. Số lá (lá/cây): đếm tất cả số lá thật trên cây. Lá thật được tính khi nhìn thấy rõ cuống lá và phiến lá. Số nụ (nụ/cây): đếm tất cả các nụ hoa trên cây. Số hoa (hoa/cây): đếm tất cả các hoa đã nở trên cây. Hoa nở được tính khi cánh hoa đã xòe ra và nhìn thấy nhị hoa.

Phương pháp xác định thành phần lý hóa tính của giá thể: pHH2O (TCVN 5975:2007), EC

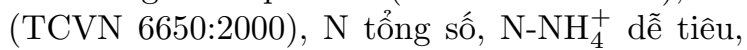
$\mathrm{P}_{2} \mathrm{O}_{5}$ tổng số, $\mathrm{K}_{2} \mathrm{O}$ tổng số, $\mathrm{CEC}$, độ rỗng (SFRI, 1998).

Số liệu thu thập được tính toán bằng phần mềm Microsoft Excel; phân tích ANOVA, xếp hạng Duncan ở mức $\alpha=0,01$ hoặc $\alpha=0,05$ bằng chương trình SAS 9.1.

\section{Kết Quả và Thảo Luận}

Kết quả Bảng 1 cho thấy, các giá thể có độ chua gần trung tính đến kiềm nhẹ và đều không bị nhiễm mặn (Slavich \& Petterson, 1993). Đồng 
Bảng 1. Tính chất của giá thể được sử dụng trong thí nghiệm

\begin{tabular}{lcccccc}
\hline Chỉ tiêu & Đơn vị & $\mathrm{G} 1$ & $\mathrm{G} 2$ & $\mathrm{G} 3$ & $\mathrm{G} 4$ & $\mathrm{G} 5$ \\
\hline $\mathrm{pH}_{\mathrm{H}_{2} \mathrm{O}}(1: 5)$ & $\mathrm{mS} / \mathrm{cm}$ & 6,82 & 7,11 & 6,53 & 6,71 & 6,41 \\
$\mathrm{EC}(1: 5)$ & $\%$ & 2,25 & 2,03 & 2,16 & 2,45 & 1,85 \\
$\mathrm{~N}$ tổng số & $\%$ & 0,35 & 0,26 & 0,21 & 0,38 & 0,18 \\
$\mathrm{~N}-\mathrm{NH}_{4}^{+}$dễ tiêu & $\mathrm{mg} / 100 \mathrm{~g}$ & 1,25 & 1,29 & 1,47 & 1,52 & 0,96 \\
$\mathrm{C}$ tồng số & $\%$ & 11,06 & 12,19 & 9,11 & 13,38 & 8,17 \\
$\mathrm{C} / \mathrm{N}$ & & 31,06 & 46,88 & 43,38 & 37,84 & 45,39 \\
$\mathrm{P}_{2} \mathrm{O}_{5}$ tổng số & $\%$ & 0,11 & 0,17 & 0,28 & 0,33 & 0,08 \\
$\mathrm{~K}_{2} \mathrm{O}$ tổng số & $\%$ & 0,26 & 0,17 & 0,37 & 0,39 & 0,22 \\
$\mathrm{CEC}$ & $\mathrm{meq} / 100 \mathrm{~g}$ & 7,26 & 6,65 & 6,18 & 7,81 & 5,37 \\
Độ rỗng & $\%$ & 48,18 & 46,71 & 48,91 & 56,43 & 42,22 \\
\hline
\end{tabular}

G1: $20 \%$ phân bò : $20 \%$ xơ dừa : $40 \%$ tro trấu : $20 \%$ đất; G2: $20 \%$ phân bò : $40 \%$ xơ dừa : $20 \%$ tro trấu : $20 \%$ đất; G3: $30 \%$ phân bò : $20 \%$ xơ dừa : $30 \%$ tro trấu : $20 \%$ đất; G4: $30 \%$ phân bò : $40 \%$ xơ dừa : $20 \%$ tro trấu : $10 \%$ đất; G5: $10 \%$ phân bò : $30 \%$ xơ dừa : $40 \%$ tro trấu : $20 \%$ đất.

thời, các giá thể trong thí nghiệm sau khi ủ đều có độ rỗng từ 42,22 đến 56,43\%. Hàm lượng đạm và lân tổng số trong các giá thể được đánh giá ở mức tương đối cao, hàm lượng kali tổng số ở mức trung bình và thấp (Rayment \& Lyons, 2011). Hàm lượng đạm dễ tiêu $\left(\mathrm{N}-\mathrm{NH}_{4}^{+}\right)$đều ở mức thấp. Đồng thời, khả năng trao đổi cation của các giá thể đều ở mức trung bình và thấp, do đó cần cung cấp thêm dinh dưỡng cho quá trình sinh trưởng và phát triển của cây hoa cát tường. Tỉ lệ $\mathrm{C} / \mathrm{N}$ ở các giá thể đều ở mức cao, chứng tỏ giá thể đang trong giai đoạn phân hủy.

\section{1. Ảnh hưởng của giá thể và nồng độ phân bón lá đến chiều cao cây hoa cát tường}

Kết quả Bảng 2 cho thấy ở thời điểm 55 NST, chiều cao cây hoa cát tường bị tác động bởi các loại giá thể khác nhau, cũng như tương tác giữa giá thể và nồng độ phân bón lá. Cây cát tường được trồng trên giá thể $30 \%$ phân bò : $40 \%$ xơ dừa : $20 \%$ tro trấu : $10 \%$ đất cho chiều cao tốt nhất $(34,14 \mathrm{~cm})$, tuy nhiên không khác biệt so với giá thể đối chứng nhưng khác biệt so với các giá thể còn lại ở mức rất có ý nghĩa thống kê. Đồng thời, khi trồng cây hoa cát tường trên giá thể $30 \%$ phân bò : $40 \%$ xơ dừa : $20 \%$ tro trấu : $10 \%$ đất kết hợp với phun $1,0 \mathrm{~g} / \mathrm{L}$ phân bón lá Đầu Trâu - MK 30-10-5 cho chiều cao cây cao nhất $(36,57$ $\mathrm{cm})$ và thấp nhất $(20,87 \mathrm{~cm})$ khi trồng cây hoa cát tường trên giá thể $30 \%$ phân bò : $20 \%$ xơ dừa : 30\% tro trấu : $20 \%$ đất và phun phân bón lá với nồng độ $1,0 \mathrm{~g} / \mathrm{L}$.

Ở thời điểm 70 NST, loại giá thể và nồng độ phân bón lá đều tác động riêng biệt đến chiều cao cây hoa cát tường, không có sự tương tác giữa giá thể và nồng độ phân bón lá. Chiều cao cây hoa cát tường khác biệt rất có ý nghĩa thống kê khi được trồng trên các loại giá thể khác nhau. Giá thể $30 \%$ phân bò : $40 \%$ xơ dừa : $20 \%$ tro trấu : $10 \%$ dất cho cây hoa cát tường có chiều cao tốt nhất $(46,06 \mathrm{~cm})$, tuy nhiên không khác biệt so với giá thể đối chứng nhưng khác biệt so với các giá thể còn lại trong thí nghiệm. Điều này cho thấy tính chất vật lý và hóa học trong giá thể ảnh hưởng rất nhiều đến sinh trưởng của cây hoa cát tường, cụ thể là chiều cao cây. Bên cạnh đó, nồng độ phân bón lá cũng ảnh hưởng đến chiều cao cây ở mức có ý nghĩa thống kê. Chiều cao cây hoa cát tường khi phun các nồng độ phân bón lá khác nhau $0,5,1,0$ và $2,0 \mathrm{~g} / \mathrm{L}$ lần lượt là 44,16 , 40,97, 43,98 cm. Kết quả Bảng 2 cũng cho thấy không có ảnh hưởng tương tác giữa giá thể và nồng độ phân bón lá đến chiều cao cây hoa cát tường. Giá thể 30\% phân bò : $40 \%$ xơ dừa : $20 \%$ tro trấu : $10 \%$ đất và nồng độ phân bón lá 2,0 g/L cho giá trị chiều cao cây đạt $46,80 \mathrm{~cm}$. Nhìn chung, khi trồng cây hoa cát tường trên giá thể $30 \%$ phân bò : $40 \%$ xơ dừa : $20 \%$ tro trấu : $10 \%$ đất kết hợp phun phân bón lá ở nồng độ $2,0 \mathrm{~g} / \mathrm{L}$ cho chiều cao cây cuối cùng tốt nhất, tuy nhiên không khác biệt so với nghiệm thức đối chứng.

\section{2. Ảnh hưởng của giá thể và nồng độ phân bón lá đến số lá trên cây hoa cát tường}

Ở thời điểm 50 NST, các loại giá thể khác nhau ảnh hưởng đến số lá cây hoa cát tường. Số lá cây hoa cát tường khác biệt rất có ý nghĩa thống kê khi được trồng trên các loại giá thể khác nhau, tuy nhiên không có khác biệt thống kê của ảnh hưởng các nồng độ phân bón lá khác nhau cũng 
Bảng 2. Ảnh hưởng của giá thể và nồng độ phân bón lá đến chiều cao $(\mathrm{cm})$ cây hoa cát tường

\begin{tabular}{|c|c|c|c|c|c|}
\hline \multirow{2}{*}{$\begin{array}{l}\text { Thời điểm } \\
\text { (NST) }\end{array}$} & \multirow{2}{*}{ Giá thể } & \multicolumn{3}{|c|}{ Nồng độ phân bón lá (g/L) } & \multirow{2}{*}{$\mathrm{TB}(\mathrm{G})$} \\
\hline & & 0,5 & $1,0(\mathrm{DC})$ & 2,0 & \\
\hline \multirow{7}{*}{55} & $20 \%$ PB : $20 \%$ XD : $40 \%$ TT : $20 \%$ Đ (ĐC) & $34,43^{\mathrm{ab}}$ & $29,67^{\mathrm{cd}}$ & $33,03^{\mathrm{abc}}$ & $32,38^{\mathrm{a}}$ \\
\hline & $20 \%$ PB : $40 \%$ XD : $20 \%$ TT : $20 \%$ Đ & $30,50^{\mathrm{bcd}}$ & $28,07^{\mathrm{d}}$ & $29,07^{\mathrm{cd}}$ & $29,21^{\mathrm{b}}$ \\
\hline & $30 \%$ PB : $20 \%$ XD : $30 \%$ TT : $20 \%$ Đ & $28,67^{\mathrm{cd}}$ & $20,87^{\mathrm{d}}$ & $30,87^{\mathrm{bcd}}$ & $26,80^{\mathrm{b}}$ \\
\hline & $30 \%$ PB : $40 \%$ XD : $20 \%$ TT $: 10 \%$ Đ & $29,67^{\mathrm{cd}}$ & $36,57^{\mathrm{a}}$ & $36,17 \mathrm{a}$ & $34,14^{\mathrm{a}}$ \\
\hline & $10 \%$ PB : $30 \%$ XD : $40 \%$ TT : $20 \%$ Đ & $27,57^{\mathrm{d}}$ & $26,43^{\mathrm{d}}$ & $26,23^{\mathrm{d}}$ & $26,74^{\mathrm{d}}$ \\
\hline & $\mathrm{TB}(\mathrm{P})$ & 30,17 & 28,32 & 31,07 & \\
\hline & $\mathrm{CV}(\%)=8,10 ; \mathrm{F}_{\mathrm{G}}=12,69^{* *} ; \mathrm{F}_{\mathrm{P}}=1,12^{\mathrm{ns}}$ & $\mathrm{G} \times \mathrm{P}=2$ & & & \\
\hline \multirow{7}{*}{70} & $20 \%$ PB : $20 \%$ XD : $40 \%$ TT : $20 \%$ Đ (ĐC) & 47,42 & 42,43 & 47,47 & $45,77^{\mathrm{a}}$ \\
\hline & $20 \%$ PB : $40 \%$ XD : $20 \%$ TT : $20 \%$ Đ & 44,00 & 41,77 & 44,73 & $43,50^{\mathrm{ab}}$ \\
\hline & $30 \%$ PB : $20 \%$ XD : $30 \%$ TT $: 20 \%$ Đ & 42,40 & 36,40 & 43,97 & $40,92^{\mathrm{bc}}$ \\
\hline & $30 \%$ PB : $40 \%$ XD : $20 \%$ TT : $10 \%$ Đ & 46,47 & 44,90 & 46,80 & $46,06^{\mathrm{a}}$ \\
\hline & $10 \% \mathrm{~PB}: 30 \% \mathrm{XD}: 40 \% \mathrm{TT}: 20 \% \mathrm{D}$ & 40,53 & 39,37 & 36,93 & $38,94^{\mathrm{c}}$ \\
\hline & $\mathrm{TB}(\mathrm{P})$ & $44,16^{\mathrm{a}}$ & $40,97^{\mathrm{b}}$ & $43,98^{\mathrm{a}}$ & \\
\hline & $\mathrm{CV}(\%)=8,0 ; \mathrm{F}_{\mathrm{G}}=7,16^{* *} ; \mathrm{F}_{\mathrm{P}}=4,03^{*} ; \mathrm{F}_{\mathrm{C}}$ & $=0,9$ & & & \\
\hline
\end{tabular}

a-c Trong cùng một nhóm giá trị trung bình, các số có cùng ký tư đi kèm thể hiện sự khác biệt không có ý nghĩa thống kê; ns: không có khác biệt thống kê, *: khác biệt có ý nghĩa thống kê ở $\alpha=0,05$, **: khác biệt rất có ý nghĩa thống kê ở $\alpha=0,01$. $\mathrm{PB}$ : phân bò, XD: xơ dừa, TT: tro trấu, Đ: đất. NST: Ngày sau trồng.

Bảng 3. Ảnh hưởng của giá thể và nồng độ phân bón lá đến số lá (lá/cây) trên cây hoa cát tường

\begin{tabular}{|c|c|c|c|c|c|}
\hline \multirow{2}{*}{$\begin{array}{l}\text { Thời điểm } \\
\text { (NST) }\end{array}$} & \multirow{2}{*}{ Giá thể } & \multicolumn{3}{|c|}{ Nồng độ phân bón lá (g/L) } & \multirow{2}{*}{$\mathrm{TB}(\mathrm{G})$} \\
\hline & & 0,5 & $1,0(\mathrm{DC})$ & 2,0 & \\
\hline \multirow{7}{*}{50} & $20 \%$ PB : $20 \%$ XD : $40 \%$ TT : $20 \%$ Đ (ĐC) & 27,50 & 27,20 & 30,40 & $28,37^{\mathrm{b}}$ \\
\hline & $20 \%$ PB : $40 \%$ XD : $20 \%$ TT : $20 \%$ Đ & 28,40 & 28,00 & 24,17 & $26,86^{\mathrm{bc}}$ \\
\hline & $30 \%$ PB : $20 \%$ XD : $30 \%$ TT : $20 \%$ Đ & 22,44 & 21,67 & 23,60 & $22,57^{\mathrm{c}}$ \\
\hline & $30 \% \mathrm{~PB}: 40 \% \mathrm{XD}: 20 \% \mathrm{TT}: 10 \%$ Đ & 30,76 & 34,91 & 32,67 & $32,78^{\mathrm{a}}$ \\
\hline & $10 \% \mathrm{~PB}: 30 \% \mathrm{XD}: 40 \% \mathrm{TT}: 20 \%$ Đ & 27,33 & 23,22 & 20,27 & $23,61^{\mathrm{c}}$ \\
\hline & $\mathrm{TB}(\mathrm{P})$ & 27,29 & 27,00 & 26,22 & \\
\hline & $\mathrm{CV}(\%)=16,07 ; \mathrm{F}_{\mathrm{G}}=8,01^{* *} ; \mathrm{F}_{\mathrm{P}}=0,25^{\mathrm{ns}} ; \mathrm{l}$ & $\mathrm{G} \times \mathrm{P}=$ & $1,00^{\mathrm{ns}}$ & & \\
\hline \multirow{7}{*}{60} & $20 \%$ PB : $20 \%$ XD : $40 \%$ TT : $20 \%$ Đ (ĐC) & 69,83 & 64,70 & 69,20 & $67,91^{\mathrm{a}}$ \\
\hline & $20 \%$ PB : $40 \%$ XD : $20 \%$ TT : $20 \%$ Đ & 58,60 & 69,70 & 56,27 & $61,52^{\mathrm{a}}$ \\
\hline & $30 \%$ PB : $20 \%$ XD : $30 \%$ TT $: 20 \%$ Đ & 52,00 & 45,10 & 53,00 & $50,03^{\mathrm{b}}$ \\
\hline & $30 \%$ PB : $40 \%$ XD : $20 \%$ TT : $10 \%$ Đ & 67,90 & 56,00 & 66,00 & $63,30^{\mathrm{a}}$ \\
\hline & $10 \% \mathrm{~PB}: 30 \% \mathrm{XD}: 40 \% \mathrm{TT}: 20 \% \mathrm{D}$ & 52,97 & 66,43 & 57,67 & $59,02^{\mathrm{a}}$ \\
\hline & $\mathrm{TB}(\mathrm{P})$ & 60,26 & 60,39 & 60,43 & \\
\hline & $\mathrm{CV}(\%)=14,90 ; \mathrm{F}_{\mathrm{G}}=4,82^{* *} ; ; \mathrm{F}_{\mathrm{P}}=0,0$ & $\mathrm{G} \times \mathrm{P}$ & $1,54^{\mathrm{ns}}$ & & \\
\hline
\end{tabular}

a-b Trong cùng một nhóm giá trị trung bình, các số có cùng ký tự đi kèm thể hiện sự khác biệt không có ý nghĩa thống kê; ns: không có khác biệt thống kê, *: khác biệt có ý nghĩa thống kê ở $\alpha=0,05$, **: khác biệt rất có ý nghĩa thống kê ở $\alpha=0,01$.

PB: phân bò, XD: xơ dừa, TT: tro trấu, Đ: đất. NST: Ngày sau trồng.

như tương tác giữa giá thể và nồng độ phân bón lá (Bảng 3). Cát tường được trồng trên giá thể $30 \%$ phân bò: $40 \%$ xơ dừa : $20 \%$ tro trấu : $10 \%$ đất có số lá nhiều nhất (32,78 lá/cây) khác biệt rất có ý nghĩa thống kê so với các loại giá thể còn lại, thấp nhất (22,57 lá/cây) khi được trồng trên giá thể $30 \%$ phân bò : $20 \%$ xơ dừa : $30 \%$ tro trấu : $20 \%$ đất.

Ở thời điểm $60 \mathrm{NST}$, số lá cây hoa cát tường tăng nhanh ở các nghiệm thức. Ở giai đoạn này chỉ có giá thể ảnh hưởng đến số lá cây hoa cát tường. Cây hoa cát tường được trồng trên giá thể đối chứng $20 \%$ phân bò: $20 \%$ xơ dừa: $40 \%$ tro trấu : $20 \%$ đất cho số lá nhiều vượt trội $(67,91$ lá/cây), tuy nhiên chỉ khác biệt với giá thể $30 \%$ phân bò : $20 \%$ xơ dừa : $30 \%$ tro trấu : $20 \%$ dất có số lá thấp nhất (50,03 lá/cây). Điều này cho thấy tính chất vật lý và hóa học trong giá thể ảnh 
Bảng 4. Ảnh hưởng của giá thể và nồng độ phân bón lá đến số nụ (nụ/cây) trên cây hoa cát tường qua các giai đoạn

\begin{tabular}{|c|c|c|c|c|c|}
\hline \multirow{2}{*}{$\begin{array}{c}\text { Thời diểm } \\
\text { (NST) }\end{array}$} & \multirow{2}{*}{ Giá thể } & \multicolumn{3}{|c|}{ Nồng độ phân bón lá (g/L) } & \multirow{2}{*}{ TB $(G)$} \\
\hline & & 0,5 & $1,0(\mathrm{DC})$ & 2,0 & \\
\hline \multirow{7}{*}{78} & $20 \%$ PB $: 20 \%$ XD : $40 \%$ TT $: 20 \%$ Đ (ĐC) & 13,55 & 13,22 & 14,57 & $13,78^{\mathrm{a}}$ \\
\hline & $20 \% \mathrm{~PB}: 40 \% \mathrm{XD}: 20 \% \mathrm{TT}: 20 \% \mathrm{D}$ & 12,06 & 13,27 & 13,22 & $12,85^{\mathrm{ab}}$ \\
\hline & $30 \% \mathrm{~PB}: 20 \% \mathrm{XD}: 30 \% \mathrm{TT}: 20 \% \mathrm{D}$ & 12,00 & 9,11 & 9,93 & $10,35^{\mathrm{c}}$ \\
\hline & $30 \% \mathrm{~PB}: 40 \% \mathrm{XD}: 20 \% \mathrm{TT}: 10 \% \mathrm{D}$ & 14,56 & 15,47 & 12,57 & $14,20^{\mathrm{a}}$ \\
\hline & $10 \% \mathrm{~PB}: 30 \% \mathrm{XD}: 40 \% \mathrm{TT}: 20 \% \mathrm{D}$ & 11,33 & 12,17 & 9,75 & $11,08^{\mathrm{bc}}$ \\
\hline & $\mathrm{TB}(\mathrm{P})$ & 12,70 & 12,65 & 12,01 & \\
\hline & \multicolumn{5}{|c|}{$\mathrm{CV}(\%)=18,39 ; \mathrm{F}_{\mathrm{G}}=4,83^{* *} ; \mathrm{F}_{\mathrm{P}}=0,42^{\mathrm{ns}} ; \mathrm{F}_{\mathrm{G} \times \mathrm{P}}=0,88^{\mathrm{ns}}$} \\
\hline
\end{tabular}

a-c Trong cùng một nhóm giá trị trung bình, các số có cùng kí tự đi kèm thể hiện sự khác biệt không có ý nghĩa thống kê; ns: không có khác biệt thống kê, **: khác biệt rất có ý nghĩa thống kê ở $\alpha=0,01$.

PB: phân bò, XD: xơ dừa, TT: tro trấu, Đ: đất. NST: Ngày sau trồng.

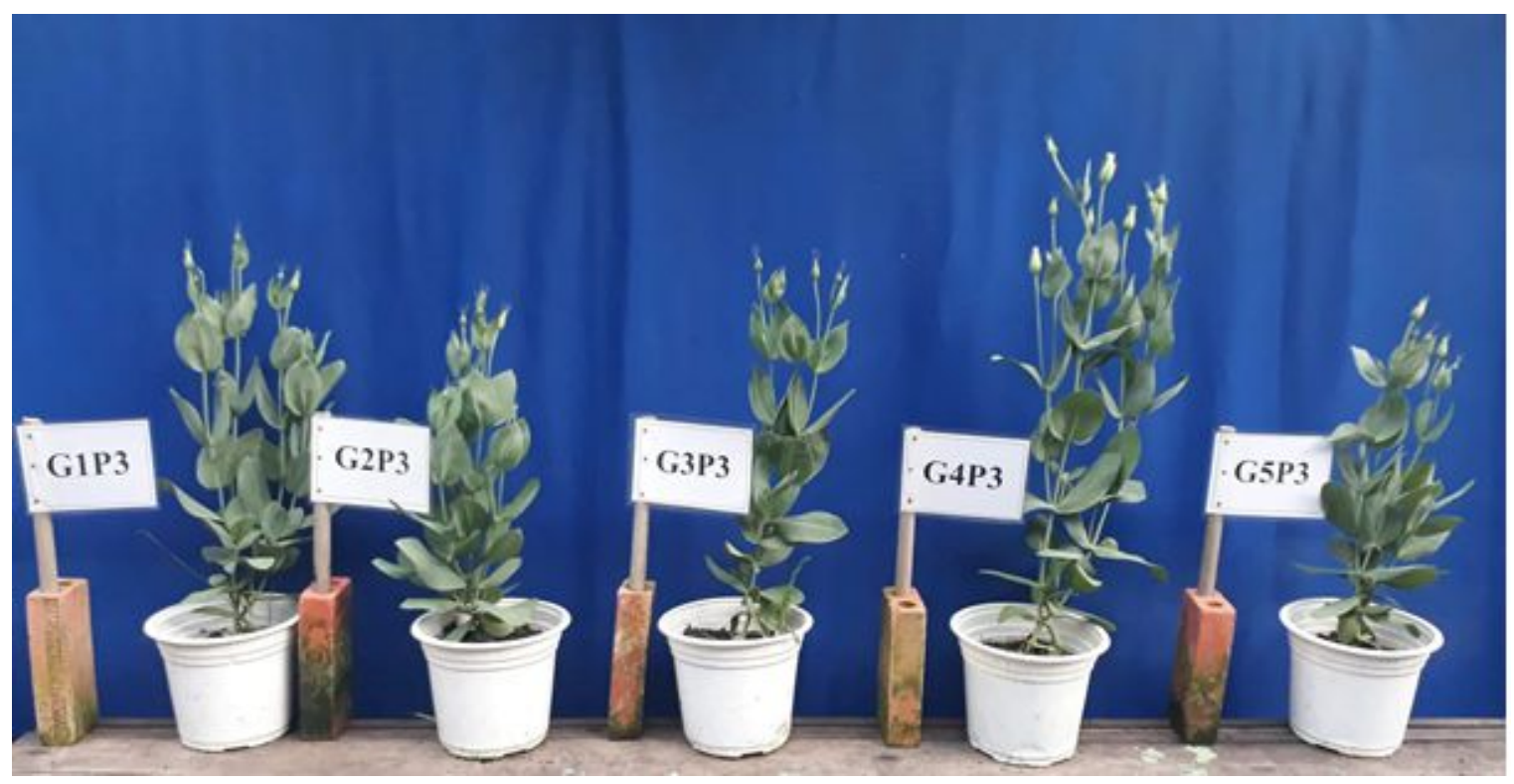

Hình 1. Số nụ trên cây hoa cát tường ở một số nghiệm thức tại thời điểm 65 NST.

Bảng 5. Ảnh hưởng của giá thể và nồng độ phân bón lá đến số hoa (hoa/cây) trên cây hoa cát tường

\begin{tabular}{|c|c|c|c|c|c|}
\hline \multirow{2}{*}{$\begin{array}{c}\text { Thời điểm } \\
\text { (NST) }\end{array}$} & \multirow{2}{*}{ Giá thể } & \multicolumn{3}{|c|}{ Nồng độ phân bón lá $(\mathrm{g} / \mathrm{L})$} & \multirow{2}{*}{ TB $(\mathrm{G})$} \\
\hline & & 0,5 & $1,0(\mathrm{DC})$ & 2,0 & \\
\hline \multirow{7}{*}{87} & $20 \%$ PB : $20 \%$ XD : $40 \%$ TT $: 20 \%$ Đ (ĐC) & 7,44 & 7,00 & 7,11 & $7,18^{\mathrm{a}}$ \\
\hline & $20 \% \mathrm{~PB}: 40 \% \mathrm{XD}: 20 \% \mathrm{TT}: 20 \% \mathrm{D}$ & 6,11 & 6,89 & 6,00 & $6,33^{\mathrm{abc}}$ \\
\hline & $30 \%$ PB : $20 \%$ XD $: 30 \%$ TT $: 20 \%$ Đ & 5,81 & 4,39 & 5,83 & $5,34^{\mathrm{c}}$ \\
\hline & $30 \% \mathrm{~PB}: 40 \% \mathrm{XD}: 20 \% \mathrm{TT}: 10 \% \mathrm{Ð}$ & 6,18 & 7,53 & 6,42 & $6,71^{\mathrm{ab}}$ \\
\hline & $10 \% \mathrm{~PB}: 30 \% \mathrm{XD}: 40 \% \mathrm{TT}: 20 \% \mathrm{D}$ & 5,50 & 5,83 & 4,92 & $5,42^{\mathrm{bc}}$ \\
\hline & TB (P) & 6,21 & 6,33 & 6,06 & \\
\hline & \multicolumn{5}{|c|}{$\mathrm{CV}(\%)=21,04 ; \mathrm{F}_{\mathrm{G}}=3,43^{*} ; \mathrm{F}_{\mathrm{P}}=0,16^{\mathrm{ns}} ; \mathrm{F}_{\mathrm{G} \times \mathrm{P}}=0,71^{\mathrm{ns}}$} \\
\hline
\end{tabular}

a-c Trong cùng một nhóm giá trị trung bình, các số có cùng ký tự đi kèm thể hiện sự khác biệt không có ý nghĩa thống kê; ns: không có khác biệt thống kê, *: khác biệt có ý nghĩa thống kể ở $\alpha=0,05$.

PB: phân bò, XD: xơ dừa, TT: tro trấu, Đ: đất. NST: Ngày sau trồng. 
hưởng rất nhiều đến sinh trưởng của cây hoa cát tường, cụ thể là số lá. Tuy nhiên, nồng độ phân bón lá không ảnh hưởng đến số lá cây hoa cát tường cũng như tương tác giữa giá thể và nồng độ phân bón lá. Số lá cây hoa cát tường khi phun các nồng độ phân bón lá khác nhau dao động từ 60,26 - 60,43 lá/cây. Số lá trên cây hoa cát tường không bị ảnh hưởng bởi tương tác giữa giá thể và nồng độ phân bón lá. Giá thể $30 \%$ phân bò: $40 \%$ xơ dừa : $20 \%$ tro trấu : $10 \%$ đất và nồng độ phân bón lá 2,0 g/L cho cây cát tường có 66,00 lá/cây.

\section{3. Ảnh hưởng của giá thể và nồng độ phân bón lá đến số nụ trên cây hoa cát tường}

Ở thời điểm 78 NST, số nụ trên cây hoa cát tường được trồng ở các loại giá thể khác nhau khác biệt rất có ý nghĩa thống kê, kêt quả được trình bày ở Bảng 4 .

Trong khi nồng độ phân bón lá khác nhau cũng như tương tác giữa giá thể với nồng độ phân bón lá không ảnh hưởng đến số nụ trên cây hoa cát tường (Hình 1). Giá thể $30 \%$ phân bò : $40 \%$ xơ dừa : $20 \%$ tro trấu : $10 \%$ đất cho số nụ trung bình nhiều nhất (14,2 nụ/cây) không khác biệt so với giá thể đối chứng, nhưng khác biệt với các giá thể còn lại trong thí nghiệm; thấp nhất là 11,08 (nụ /cây) khi trồng cây hoa cát tường trên giá thể $10 \%$ phân bò : $30 \%$ xơ dừa : $40 \%$ tro trấu : $20 \%$ đất. Cây hoa cát tường được trồng trên giá thể $30 \%$ phân bò : $40 \%$ xơ dừa : $20 \%$ tro trấu : $10 \%$ đất kết hợp phun phân bón lá ở nồng độ $1,0 \mathrm{~g} / \mathrm{L}$ cho số nụ đạt 15,47 nụ/cây.

\section{4. Ảnh hưởng của giá thể và nồng độ phân bón lá đến số hoa trên cây hoa cát tường}

Kết quả Bảng 5 cho thấy ở thời điểm 87 NST, số hoa ở tất cả các nghiệm thức đều tăng. Các giá thể khác nhau có ảnh hưởng đến số hoa, trong đó nghiệm thức có giá thể đối chứng $20 \%$ phân bò : $20 \%$ xơ dừa : $40 \%$ tro trấu : $20 \%$ đất có số hoa nhiều nhất (7,18 hoa/cây) nhưng không khác biệt thống kê so với giá thể $30 \%$ phân bò : $40 \%$ xơ dừa : $20 \%$ tro trấu : $10 \%$ dất và $20 \%$ phân bò : $40 \%$ xơ dừa : $20 \%$ tro trấu : $20 \%$ đất. Giá thể $30 \%$ phân bò : $20 \%$ xơ dừa : $30 \%$ tro trấu : $20 \%$ đất cho số hoa thấp nhất (5,34 hoa/cây). Trong giai đoạn này, nồng độ phân bón lá khác nhau và tương tác giá thể với phân bón lá cũng không ảnh hưởng đến số hoa trên cây hoa cát tường. Cây hoa cát tường được trồng trên giá thể $30 \%$ phân bò : $40 \%$ xơ dừa : $20 \%$ tro trấu : $10 \%$ đất kết hợp phun phân bón lá ở nồng độ $1,0 \mathrm{~g} / \mathrm{L}$ cho số hoa đạt 7,53 hoa/cây.

\section{Kết Luận}

Các loại giá thể được sử dụng trong thí nghiệm có tác động rõ rệt đến sinh trưởng và phát triển của cây hoa cát tường. Cây hoa cát tường được trồng trên giá thể $30 \%$ phân bò : $40 \%$ xơ dừa : $20 \%$ tro trấu : $10 \%$ đất cho kết quả vượt trội về chiều cao cây $(46,06 \mathrm{~cm})$, số lá (63,30 lá/cây), số nụ (14,20 nụ/cây) và số hoa (6,71 hoa/cây). Trong khi đó, trên cùng một nền giá thể, việc phun các nồng độ phân bón lá Đầu Trâu MK 3010-5 chỉ tác động đến chiều cao cây hoa cát tường nhưng không ảnh hưởng đến các chỉ tiêu về phát triển.

\section{Lời Cam Đoan}

Chúng tôi cam đoan bài báo do nhóm tác giả thực hiện và không có bất kỳ mâu thuẫn nào giữa các tác giả.

\section{Tài Liệu Tham Khảo (References)}

Bui, H. H. (2013). Organic fertilizers in sustainable agricultural production in Vietnam. In National Workshop on Improving the Efficiency of Fertilizer and Use in Vietnam (578-591). Ho Chi Minh City, Vietnam: Agricultural Publishing House.

HCMCPC (Ho Chi Minh City People's Committee). (2016). Decision No. 536/QD-UBND dated February 05, 2016 on approving the flower growing program in the city for the period of 2016 - 2020. Ho Chi Minh City, Vietnam: Ho Chi Minh City People's Committee.

Olle, M., Ngouajio, M., \& Siomos, A. (2012). Vegetable quality and productivity as influenced by growing medium: a review. Agriculture 99(4), 399-408.

Rayment, G. E., \& Lyons, D. J. (2011). Soil chemical methods - Australasia. Collingwood, Australia: CSIRO publishing.

SFRI (Soils and Fertilizers Research Institute). (1998). Handbook of soil, fertilizer and crop analysis. Ha Noi, Vietnam: Agricultural Pusblishing House.

Slavich, P. G., \& Petterson, G. H. (1993). Estimating the electrical conductivity of saturated paste extracts from 1:5 soil, water suspensions and texture. Australian Journal of Soil Research 31(1), 73-81.

Tran, L. T. N. (2015). The micropropagation of Lisianthus (Eustoma grandiflorum L.) through the way of organogenesis and embryogenesis. An Giang University Journal of Science 11(3), 110-118. 